\title{
Arbor
}

\section{Testimonios arqueológicos del Oriente Próximo reflejados en el Séfer-Masa `ot de Benjamín de Tudela (Siria-Palestina, Mesopotamia y Egipto)}

\section{José Ramón Magdalena Nom de Déu}

Arbor CLXXX, 711-712 (Marzo-Abril 2005), 465-488 pp.

\section{Benjamín de Tudela: breve esbozo biográfico}

Benjamín de Tudela (en hebreo Biniamín ben rabbi Yonah miTudela) es, sin duda, un navarro universal. Judío de la aljama tudelana ${ }^{1}$, se ignora la fecha de su nacimiento (acaso hacia 1130). Hijo de rabino y viajero infatigable, sólo sabemos de este personaje lo poco que de él se menciona en su famoso Libro de Viajes o Séfer-masa'ot, fruto de sus vivas experiencias -las más de las veces directas- exquisitamente plasmadas en su relación de viaje, redactadas en hebreo. Conocedor del romance navarro vernáculo de la época, sabía hebreo -su lengua de instrucción y cultivo literario- y árabe, entendiendo acaso el griego y el latín ${ }^{2}$. Tenía asimismo algunos conocimientos de la historia clásica ${ }^{3}$ y era experto en diversas artesanías y negocios, lo que refuerza la suposición de que fuese un mercader y su viaje una misión comercial ${ }^{4}$.

A finales de 1165 o principios de 1166 salió de su Tudela natal pasando por Zaragoza, Tortosa, Tarragona, Barcelona, Gerona, Narbona y otras localidades del sur de Francia para, desde Marsella y alternando vía marítima y terrestre, visitar Italia, Grecia, Constantinopla, Jerusalén, Bagdad, Damasco y Egipto, entre otros lugares, para regresar, hacia 1170, desde Sicilia a tierras de Castilla, como se dice en el prólogo de su relato. En él consta que era hombre inteligente e ilustrado, versado en 
la Torá y en el derecho rabinico y que en el mencionado Libro de Viajes escribió todas las cosas que vio y oyó de boca de hombres veraces ... cosas que no habian sido jamas oídas en tierras de Sefarad. En el cronicón hispanohebreo Séfer Yuhasín de Abraham Zakut se dice que Benjamín de Tudela murió en el año 1173, acaso en su Tudela natal ${ }^{5}$.

\section{El Libro de Viajes (Séfer Masa`ot): manuscritos}

Esta relación de viajes se difundió pronto entre los ambientes intelectuales del judaísmo europeo y oriental mediante copias manuscritas, donde se añadieron, sin duda, otros materiales ajenos a la pluma de Benjamín (como el prólogo anónimo y otras interpolaciones de corte fantástico y apologético), ampliando la extensión del texto básico redactado por nuestro viajero. Los cinco manuscritos -tres completos y dos fragmentarios- que de que tengo noticia son:

1) el más antiguo, de origen germánico, datado a finales del siglo XII o inicios del XIII (ms. 27.089 del British Museum)

2) ms. 26 del catálogo Sacerdote de la Biblioteca Casanatense de Roma, es del siglo XV, copiado por Isaac de Pisa en 1430

3) ms. Epstein, de Viena y de finales del siglo XV; hoy en la Biblioteca Nacional y Universitaria, Jerusalén (Israel), $\mathrm{n}^{\circ} \mathrm{Heb} 8^{\circ}$ 2647

4) ms. Oppenheim add. $8^{\circ} 36$ (folios 58-63, catalogado por Neubauer $\mathrm{n}^{\circ}$.2453) de origen hispano y considerado por Adler de los siglos XIV-XV; faltan cuatro folios detrás de los tres primeros).

5) $\mathrm{ms}$. Oppenheim add. $8^{\circ} 58$ (a partir del folio 57, catalogado por Neubauer $\mathrm{n}^{\circ} 2580$ ), le falta casi la primera mitad y es una copia tardía, acaso del siglo XVIII y de características paleográficas orientales.

El mejor manuscrito es, sin duda, el germánico o askenazí del British Museum, pues transcribe con gran fidelidad y pureza los topónimos y antropónimos y otras voces no hebreas que contiene, intentando imitar la pronunciación de la época. Algunos errores que se detectan son meramente gráficos y debidos a descuidos del escriba. Redactado a finales de siglo XII o principios del XIII, su proximidad cronológica con las aventuras reales de nuestro viajero nos permiten conjeturar una mayor pureza textual. 


\section{Ediciones}

Tal sería la fama y difusión de los relatos de Benjamín que ya aparece la primera edición impresa (editio princeps) del Séfer Masa`ot en 1543 a cargo del editor Soncino, en Istanbul. Fue, sin duda, edición descuidada y precipitada, sin que sepamos en qué manuscrito se fundamenta. Contiene numerosos errores, que se fueron perpetuando y transmitiendo posteriormente ya que sirvió de base a las posteriores y primeras traducciones al latín y a otras lenguas europeas. Se conserva un solo ejemplar de esta editio princeps, incompleto, en la Bodleyan Library de Oxford.

De esta primera se derivan: la Elzeviriana de Friburg (1553), arrastrando todos los errores antes mentados y la de Leiden (1663), que es copia de la anterior. Del mismo año es la célebre edición -mejorada y con variantes- de Constantino L'Empereur, salida de las prensas elzevirianas y reedición del texto de Friburg con algunas variantes. De Amsterdam y de 1696 es la de Gaspar Stern, reproducida en 1734. Otra reimpresión de la Elzeviriana es la de Michael Nagel, publicada en Leiden en 1762, con fines didácticos. Por último, la edición de Sulzbach de 1782 es una desastrosa copia del texto de L'Empereur.

La segunda edición fundamental apareció en Ferrara, 1556, de los talleres de Abraham ben Usque. Se conserva un ejemplar completo en la Bodleyan Library de Oxford.

Otras ediciones no basadas en manuscritos conocidos son: la de Amsterdam (1698) por Eliaquim ben Jacob Hazzan (reimpresa quizás en 1734) y las de Varsovia (1844), Zolkiew (1862) y Lemberg (1859).

La edición de Asher ${ }^{6}$ (London-Berlin, 1840-1841) se apoya en la ferrarense de 1556, basada en un manuscrito cercano al vienés de Epstein y que ofrece un texto mucho más depurado que la princeps.

Con los hallazgos e identificación de los manuscritos hebreos se iniciaron las modernas y más científicas ediciones críticas. El primer intento, acompañado de introducción y traducción al alemán, se lo debemos al erudito Grünhut, quien ofrece el texto del manuscrito Casanatense (Jerusalén 1903).

Por último -y mientras no aparezca otra edición que la supere-, la que con toda justicia podríamos calificar como mejor y más cuidada edición crítica es la de Adler ${ }^{7}$, complemento de las de Asher (a la que frecuentemente se remite) y de Grünhut. Apareció en London (1907) y se fundamenta en el manuscrito del British Museum, ofreciendo un aparato crítico con las variantes de los otros manuscritos conocidos así como copiosas notas aclaratorias a la pulcra traducción inglesa. 


\section{Traducciones}

La primera traducción -precisamente al latín- del Séfer Masa`ot se debe al hebraísta español Benito Arias Montano. Se basa en la editio princeps (hebrea) de 1543 y apareció en Amberes en 1575, y lleva el largo título Itinerarium Beniamini Tudelensis in quo res memorabiles, quas ante quadringentos annos totum fere terrarum orbem notatis itineribus dimensis vel ipse vide vel a fide dignis suae aetatis hominibus accepit, breviter atque dilucide describuntur; ex hebraico latinum factum Bened. Arias Montano interprete. De ésta deriva la edición de 1636, salida de las prensas calixtinas de Helmstadt, que incluye sendas interpolaciones de las descripciones de La Meca y Medina (ciudades que nunca visitara Benjamín) acaso extraídas de los itinerarios de Wartomann y Wild. Esta edición fue reproducida -y algo mejorada- por las prensas de Teubner, Leipzig 1664 .

Asimismo de la pionera traducción de Arias Montano proceden la inglesa de la serie Purchas's Pilgrims (London 1625) y la francesa de Bergeron, incluida en la Collection de Voyages, faits principalement en Asie, dans le XII, XIII, XIV et XV siècles, La Haye 1735, (reeditada en París 1830).

Otra traducción latina es la de Constantin l'Empereur, acompañada del texto hebreo de la edición de Friburg de 1583 y salida de las prensas elzevirianas en 1633. Esta traducción va precedida de una cruel crítica a la primera versión latina de Arias Montano, si bien es cierto que le corrige muy pocos errores al tiempo que los aumenta en la suya, llena de absurdos y cuajada de inútiles y pedantes notas eruditas. Este texto latino de L'Empereur sirvió de base para la versión al flamenco (Leyden 1666) y las dos al yídico o judeoalemán (Amsterdam 1691 y Frankfurt 1711).

Otras traducciones inglesas son la de Harris (London 1744), basada en las latinas de Arias Montano y L'Empereur. Muy deficiente es la del reverendo Gerrans (London 1783). Ya en el siglo XIX, un resumen en inglés del Séfer Masa`ot apareció en la General Collection of the best and most interesting Voyages and Travels of the World (volumen VII, London 1808-1814). La traducción inglesa que acompaña la edición del texto hebreo de Asher (London-Berlin 1840-1841) representa ya un notable avance con respecto a las precedentes, si bien todavía acarrea deficiencias y errores al no estar basada en la lectura directa de los manuscritos. Esta traducción la reproduce Wright -al pie de la letra- en sus Early Travels in Palestine (London 1848) y de ella derivan, al parecer, la holandesa de 
Testimonios arqueológicos del Oriente Próximo...

Keyzer (Leyden 1847) y la francesa del rabino Carmoly ${ }^{8}$ (Bruxelles-Leipzig 1852).

Finalmente, la versión inglesa de Adler (London 1907) que -acompaña la edición crítica del texto hebreo- corrige las inexactitudes de Asher y, a la luz de los manuscritos, ofrece la más cuidada y seria investigación textual. Antes cité la traducción alemana de Grünhut, basada en el ms. Casanatense (Jerusalén 1903) y tengo noticia de una traducción al ruso a cargo de Margolin (Sankt Peterburg 1881) y otra al judeoárabe (Bagdad, s. f.), pero no las he podido localizar.

La primera traducción castellana -basada en el texto hebreo de Asher y posteriormente adaptada al de Adler- es la tesis de doctorado del semitista Ignacio Agustín González Llubera y lleva por título Viajes de Benjamín de Tudela. 1160-1173. Por primera vez traducidos al castellano con introducción, aparato crítico y anotaciones. Madrid 1918. Por último, quien estas notas suscribe es autor de una segunda traducción del Séfer Masa`ot, basándome en el texto de Adler y bibliografía complementaria más actualizada: Libro de viajes de Benjamín de Tudela. Versión castellana, introducción y notas. Barcelona 1982 [ $2^{2}$ edición 1989], que acompaña al texto hebreo y la versión euskera en Benjamin Tuteraoka. Bidaien Luburua. Libro de Viajes. Benjamín de Tudela. Pamplona 1994. También se reeditó en una edición popular: Benjamín de Tudela. Libro de Viajes. Biblioteca Básica Navarra. Pamplona 2002.

\section{El itinerario}

El itinerario, como se dijo más arriba, se inicia en Tudela, pasando por Aragón y Cataluña -donde da escasas aunque interesantes noticias sobre estos judíos hispánicos del siglo XII- Francia meridional, Génova, Roma, Salerno, pasando a territorio del Imperio Bizantino, ofreciendo una magna descripción de la fastuosa Constantinopla, pasa por Siria y la Palestina de los cruzados, visita los Santos Lugares de Jerusalén, Belén y Nablus, se traslada a Damasco, Alepo, Racca y Mosul, y por el valle del Tigris llega a la capital califal, Bagdad. Allí debió residir largo tiempo acogido en el seno de la opulenta aljama judía bagdadí -que con todo lujo de detalles nos describe- atraído por los posibles pingües beneficios ofrecidos en tan importante y rico centro mercantil y cultural. Bagdad sería el centro de operaciones y viajes menores por el área, quizás hasta Basora, en la Baja Mesopotamia.

Tras unos fantásticos viajes -acaso nunca realizados y obra de posteriores compiladores y redactores de los manuscritos- por tierras de India y 
China, el relato se vuelve más realista y verosímil al tratar de Egipto: El Cairo, la vieja Fustat, Alejandría, el Monte Sinaí y Damietta, desde donde embarcó hacia Sicilia y, desde esta isla, según su relato, Benjamín va a Roma por segunda vez y, pasando por Lucca y Verdún, llegaría a París, donde bruscamente se termina el relato. Con todo, esta parte final del texto hebreo-que se refleja en todos los manuscritos-parece que no la redactó el propio Benjamín, sino que sería producto de la fértil imaginación de algún compilador-redactor askenazí. Esta interpolación incluye una idílica descripción de las comunidades judías del valle de Rhin, con referencias poco fiables a Bohemia, Esclavonia y Kíev, en la Rus primitiva. Esta ambientación centroeuropea no coincide con el tono mediterráneo y oriental del resto del Séfer-masa ot. Lo más verosímil es que, como se dijo más arriba, desde Sicilia se dirigiese directamente hacia poniente, recalando en Mallorca y desde algún puerto valenciano o catalán ultimase su definitivo viaje de regreso hasta llegar sano y salvo a su Tudela natal ${ }^{9}$.

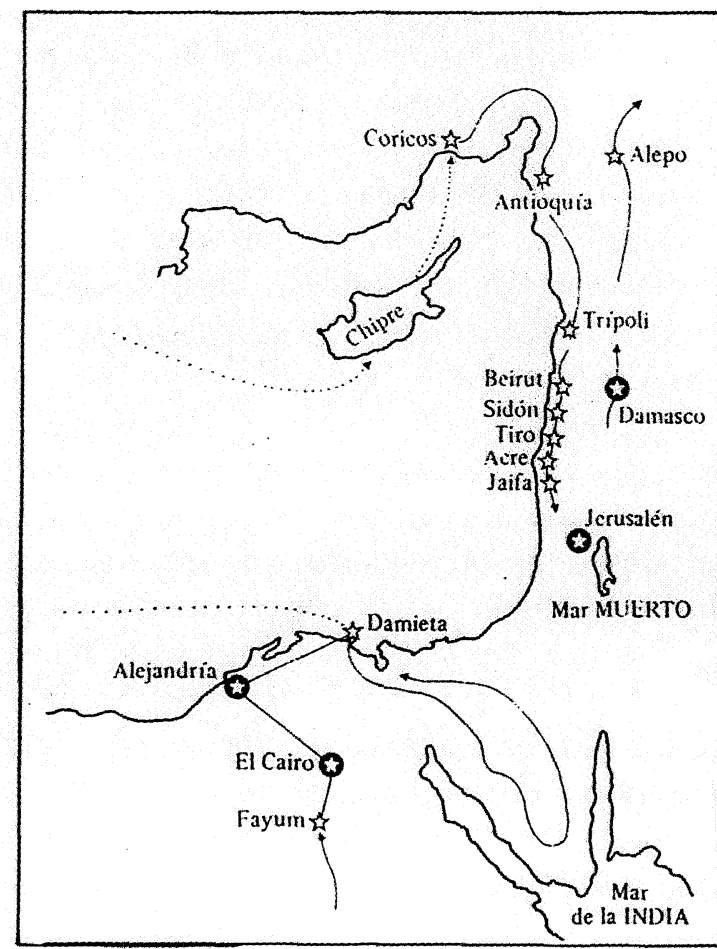

\footnotetext{
Itinerario de Benjamín de Tudela por

Siria - Palestina y Egipto (según Haim Beinart)
} 
Testimonios arqueológicos del Oriente Próximo...

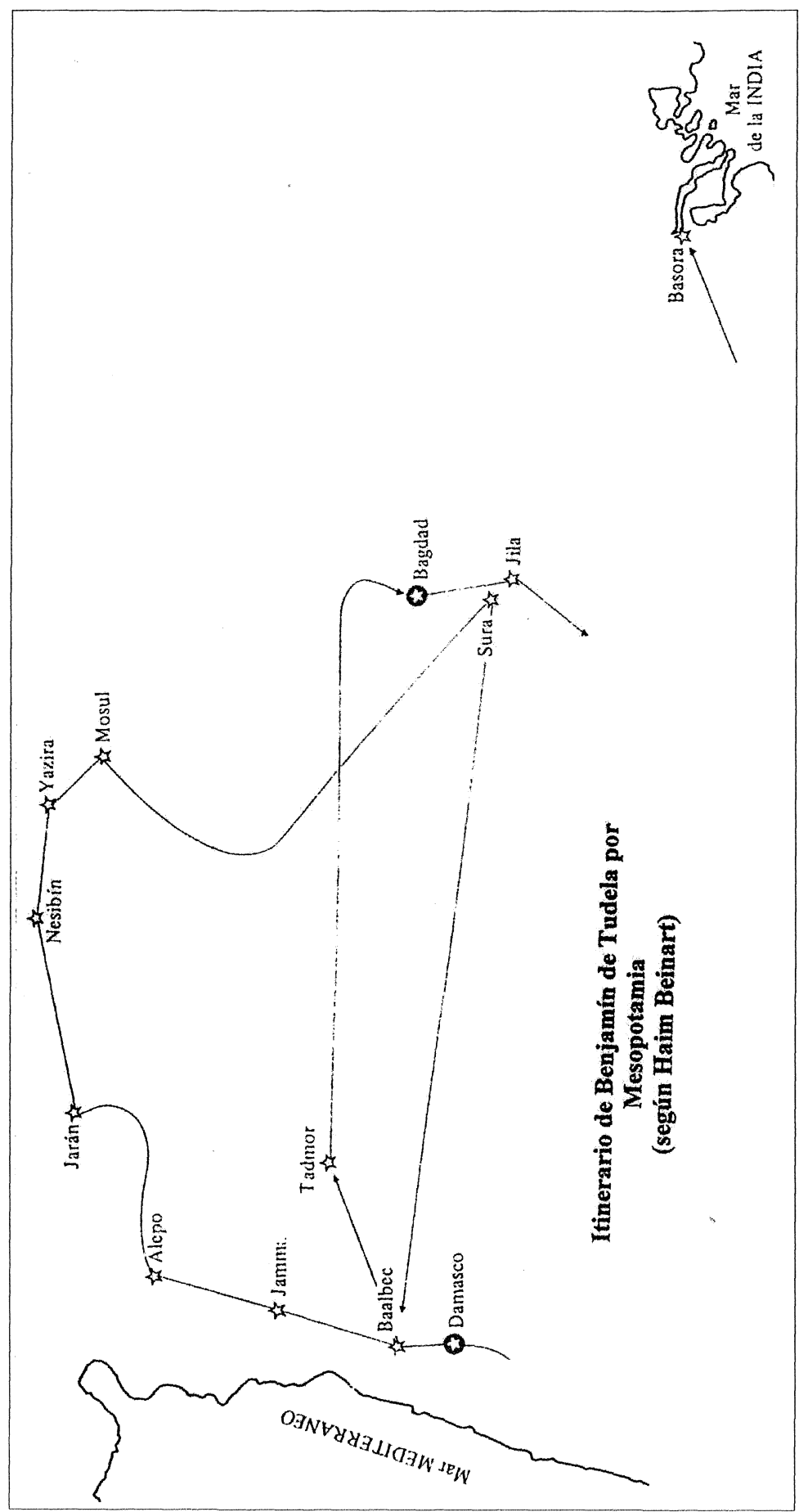


La estructura literaria de este Séfer Masa`ot es formalmente la de un itinerario. Benjamín de Tudela se interesa y pasa revista a tres aspectos fundamentales, omnipresentes en toda su relación de viaje:

1) las comunidades de judíos. Todo el itinerario es, salvo contadas excepciones, una sucesión de aljamas hebreas, en cada una de las cuales nuestro viajero buscaría ayuda e informaciones de interés -acaso recomendaciones- muy útiles en vistas a decidir las siguientes etapas de su periplo. Así, sobre la marcha y en base a los datos suministrados por sus correligionarios, Benjamín iría considerando y orientando sus pasos hacia nuevos destinos y lejanas singladuras. De cada comunidad hebrea nos ofrece datos sobre su demografía, exagerando las cifras sólo cuando las informaciones le llegan por terceras personas y no la ha podido visitar personalmente. Da cuenta, asimismo, de las principales autoridades rabínicas de cada lugar, destacando las egregias figuras de Exilarca de Bagdad y del Naggid de Egipto. Siempre tiene algún jugoso comentario acerca de la condición social de los judíos locales, bien para destacar la opresión en que se hallan sometidos -como los judíos de Costantinopla-, bien para ensalzar la gran independencia y libertades de que disfrutan -como es el caso, según exagerada descripción de Benjamín, de los judíos arábigos del Jeybar o los asentados en las lejanas montañas de Nisabur-. Describe asimismo las actividades económicas de sus hermanos de fe: médicos y funcionarios de las autoridades del país, adinerados comerciantes y armadores de barcos, artesanos vidrieros, sederos, tintoreros, sin faltar ocupaciones y menesteres más humildes como agricultores y pastores. Tampoco escapa al sagaz ojo observador de Benjamín la situación religiosa y cultural de los hebreos que visita y nos da cuenta de su grado de instrucción, el número de madrazas o academias talmúdicas, las sinagogas, los santuarios y otros lugares de amorosa veneración para el pueblo judío. Ni se olvida en el tintero las oportunas anotaciones sobre las comunidades más o menos heréticas o heterodoxas de judíos, como los epicúreos de Chipre y los sectarios caraítas y samaritanos.

2) las grandes líneas de la situación política y militar en -y entre- los estados y naciones del ámbito cristiano occidental y del islámico oriental. El dilatado periplo de Benjamín le hace transitar forzosamente territorios dominados por poderes políticos, creencias religiosas y entidades étnicas diversos. Tal diversidad supondría riesgos y peligros ocasionales a cualquier viaje emprendido desde occidente a oriente, o al contrario. Pero lo cierto es que nunca constituyó, por lo general, un serio obstáculo al trasiego de las gentes, las ideas y, acaso lo más importante, las mercaderías. Así, nuestro viajero recorrerá sin dificultad aparente los reinos 
hispánicos peninsulares, prosiguiendo por la Provenza e Italia y, tras pasar por Pisa y Lucca, visita Roma y otras ciudades de la Italia meridional y adriática; desembarca en territorio bizantino y en la fastuosa y rica Constantinopla ya detecta los primeros síntomas de la debilidad y decadencia de aquel imperio, cuyos ejércitos «reclutan mercenarios de todos los pueblos gentiles llamados bárbaros" ya que los griegos del país «carecen de espiritu combativo; se les considera, por tanto, afeminados que carecen de fuerza para resistim. El Reino Latino de Tierra Santa -efímera realización política de los cruzados europeos para facilitar y permitir las peregrinaciones cristianas a los Santos Lugares de Palestina- se hallan, al paso de Benjamín por la santa ciudad de Jerusalén, en su momento de máximo poderío militar y nuestro viajero ofrece detalles interesantes de las fuerzas de los caballeros de las órdenes del Hospital y del Temple. Curiosas son las observaciones que hace acerca de los samaritanos, afincados en Nablús, cuyos ceremoniales de pascua describe, así como sus estrictas leyes de pureza ritual y matrimonio. Critica la peculiar pronunciación del hebreo samaritano, que carece de las tres consonantes guturales típicas de las lenguas semíticas, he', het y ‘ayn, reducidas al simple ataque glotal ‘alef.

Durante la segunda mitad del siglo XII, el mundo islámico oriental asiste al irresistible empuje del imperio Salyuk por Persia y Mesopotamia. Pronto caerá el califato fatimí egipcio, enemigo del poder abbasí de Bagdad. Hay todavía otras entidades étnicas, políticas y religiosas descritas en el Séfer Masa`ot: la más importante, desde los puntos de vista político y militar, es la de los turánidos guzz, turcos o turcomanos, quienes en su fase anterior a su islamización todavía son considerados como infieles tanto por Benjamín de Tudela ${ }^{10}$ como por el granadino musulmán Abu-Hamid. Grupos sectarios del islam, como los fanáticos hašišin de las montañas libanesas, o los depravados drusos -quienes, sin embargo, mantienen cordiales relaciones con los judíos- tampoco escapan al oportuno comentario del viajero navarro. En Jerusalén menciona a los cristianos jacobitas, georgianos, griegos (ortodoxos) y francos (católicos). Cita a los monjes sirianos del monte Sinaí, a los guirguisitas, asimismo cristianos; a los alanos del Cáucaso, a los armenios y a los bandidos saqueadores valacos, en los confines del imperio Bizantino. Otras etnias que seguramente nunca conoció personalmente, pero que se citan en su relato, son: los cusitas o etíopes del alto Nilo, quienes capturan a los irracionales negros para venderlos como esclavos, como también son negros los adoradores del sol de Quilón, en la costa de Malabar; donde asimismo sus judíos son de piel oscura. 
3) los grandes centros económicos, mercantiles y artesanales de occidente y oriente y las rutas comerciales, terrestres y marítimas, que los unen o, llegado el caso, los pudiesen unir. Pues al igual que las peregrinaciones y las misiones diplomáticas, el comercio siempre fue un importante incentivo para emprender viajes. Y si grande es el interés que Benjamín muestra por la situación de las comunidades hebreas que visita no por ello deja de prestar menor atención a los recursos económicos y posibilidades de cada lugar o país por donde pasa: la producción agrícola, la pesca, las artesanías, las manufacturas y el tráfico comercial. Además de indicarnos en varias ocasiones que sus correligionarios se dedican a menesteres agrícolas o ganaderos, nuestro viajero nos aporta copiosas referencias sobre la feracidad de huertas y vergeles, así como sistemas de regadío, como en el caso de las tierras bajas del delta del Nilo, en Egipto, cuya rotación de cereales describe a la vez que da cuenta de la gran abundancia y diversidad de frutas, verduras y legumbres que dan sus campos. En Quilón se cultiva la pimienta negra, la caña de azúcar, el jenjibre y otras especias. El azúcar de Tiro es, sin embargo, el mejor "porque lo siembran, y acuden de todas partes a comprarlo". Cita, de pasada, la mirra aromática del lejano Tibet. Poco dice de la ganadería, si bien se detiene y describe con cierto detalle el curioso proceso evolutivo que sufren ciertas sabandijas marinas de Catifa y el peligroso sistema de pesca y extracción de las perlas, así como el ingenioso sistema de zanjas y canales empleado por los egipcios para capturar los grandes y grasientos peces del Nilo, cuando éste se desborda. Al pasar por el puerto siciliano de Trápani hace mención de la piedra de coral, aunque nada dice de las pesquerías ni del pulido de esta gema semipreciosa de origen animal. En Puzzoli se fija en el petróleo mineral, que se utiliza con finalidades medicinales.

Las actividades artesanales y pequeñas industrias de transformación de materias primas en productos manufacturados para el consumo a través de los circuitos comerciales se derivan de la producción agrícola -como la elaboración del azúcar, la pimienta y otras especias- o de la pesca -extracción de aceites y salazones- sin olvidar la elaboración de bálsamos y ungüentos a base del citado petróleo ni la manufactura del vidrio, fundiendo arenas silícieas y carbonatos minerales. Con todo, la artesanía más extendida -acaso la más lucrativa- es la relacionada con los tejidos: las sedas de Tebas y Salónica, los linos y telas finas, los encajes y brocados de Constantinopla -donde los judíos se dedican asimismo al curtido de pieles- sin olvidarse Benjamín de citar el monopolio de la tintorería, a la sazón en manos de dos judíos jerosolimitanos. 
Testimonios arqueológicos del Oriente Próximo...

Los puertos comerciales más importantes del ámbito cristiano mediterráneo son, según el Séfer-Masa`ot, los de Barcelona, Marsella, Amalfi, Egrippo, Constantinopla; los de Tiro y Ašqelón en Palestina y el de Alejandría en el Egipto fatimí. Ya en el interior de Asia, Damasco y Bagdad son los centros de enlace entre el lejano oriente y las costas levantinas. A estas urbes acuden negociantes de todas las naciones, lenguas y religiones con todo tipo de mercadería. La lejana isla de Qish es el puente comercial entre la India, Persia, Arabia y Mesopotamia, ejerciendo sus isleños el oficio de expertos corredores en el comercio de especias, tejidos lujosos y cereales.

No es el itinerario de Benjamín el del típico peregrino judío a Tierra Santa sino que, en nuestra opinión, sigue una ruta comercial más o menos preestablecida y lo suficientemente flexible como para ir cambiando de rumbo, sobre la marcha, según los datos e informaciones que recabaría de sus correligionarios al paso por cada localidad. Nuestro viajero se dirige hacia las opulentas ciudades de Oriente (Constantinopla, Damasco, Bagdad, El Cairo) posiblemente dedicado al cómodo y lucrativo comercio de telas lujosas, acaso con la intención de abrirse camino y mercado en el ámbito de la especiería, de tan pingües beneficios. El esquema general de tan largo periplo -excluyendo los fantásticos y pretendidos viajes por la India, la lejana China, Arabia y Europa germánica y eslava- se acomoda y es del todo razonable para las posibilidades y ambiciones de un arriesgado, culto y observador comerciante judío de la segunda mitad del siglo XII, como es el caso de nuestro Benjamín de Tudela.

\section{Antigüedades y restos arqueológicos orientales en el Séfer Masa`ot}

El agudo ojo observ̀ador de Benjamín de Tudela se fija asimismo -si bien de manera esporádica y ocasional- en antiguos monumentos, viejas ruinas, vestigios y restos arqueológicos de pretéritas civilizaciones del próximo oriente que guardan cierta relación con la historia bíblica y el pueblo de Israel. Y no se deja en el tintero algún que otro interesante comentario descriptivo, a veces parco -y otras excesivamente fantástico-, acerca de los relictos que encuentra a su paso.

\section{a) Canaán}

Ya en tierras libanesas, en la cananea Biblos ${ }^{11}$, se fija en el -por él denominado- templo de los amonitas, que nos describe así: 
«...desde allí hay una jornada de marcha hasta el otro Gebal, que es la frontera de los amonitas ... allí encontraron el templo que fue, en épocas remotas, de los amonitas. Asimismo está allí sentado el ídolo de los amonitas en una cátedra llamada trono. Está hecho de piedra, recubierto de oro, sendas mujeres están sentadas, una a su derecha y otra a su izquierda y ante él hay un ara donde ofrecían sacrificios y quemaban incienso en época de los amonitas."

Más al sur, pasadas Beirut, Sidón y Sarafend - de las que nada de interés arqueológico menciona- llega hasta Tiro la Nueva:

«... subiendo por la muralla ... se ve Tiro la Antigua, que está cubierta por el mar y a una distancia de tiro de piedra de la ciudad nueva. Si se quiere ir en barca, por el mar, se ven las torres, los zocos, las plazas y los palacios en el fondo del $\operatorname{mar}^{12}$..."

\section{b) Tierra de Israel}

Entrando ya en la Tierra de Israel, pasa por Acre y describe las ruinas del monte Carmelo, en Haifa, según la tradición bíblica:

"... sobre la orilla del mar. Del otro lado está el monte Karmel, sobre ella; al pie del monte hay muchos sepulcros de israelitas y en el monte está la cueva de Elías. Allí los cristianos edificaron una iglesia que llamaron San Elías. En la cima del monte se reconoce el sitio del altar derribado, que recompuso Elías, en tiempo de Ahab. El lugar que queda del altar circular es de como unos cuatro $\operatorname{codos}^{13}$..."

Y de la antigua Samaria, o Sebastia, nos dice:

«...allí se reconoce el palacio de Acab, hijo de $0 m r{ }^{14}$, en ruinas. Era una ciudad muy fortificada ..."

Llegado a la santa Jerusalén -a la sazón en manos de los cruzadosse detiene en una amena y exacta descripción de sus murallas, torres y puertas:

«...Jerusalén es una pequeña ciudad fortificada bajo tres murallas...en la muralla que está junto a la Torre de David ${ }^{15}$ se encuentra la obra de basamiento -como unos diez codos- que es construcción de los antiguos muros que edificaron nuestros antepasados. El resto es obra de los ismaelitas ${ }^{16}$. No hay en toda la ciudad un lugar más fortificado como la Torre de David ..."

Así como otros edificios, importantes tanto para los judíos como para los cristianos y los musulmanes:

«... hay allí dos casas: una, el Hospital ${ }^{17}$, del que salen cuatrocientos caballeros- y allí descansan todos los enfermos que acuden, dándoles todo 
tipo de provisión, tanto mientras viven como después de muertos. La segunda casa, llamada Templo de Salomón ${ }^{18}$, es el palacio que edificara el rey Salomón ... allí descansan los caballeros y de allí salen diariamente trescientos caballeros a guerrear, además de los que vienen del país de los francos y de tierra de cristianos, comprometiéndose mediante voto que servirán allí, días o años, hasta el cumplimiento de su promesa. Allí está la gran iglesia que llaman Sepulcro ${ }^{19}$ y allí está enterrado aquel hombre ${ }^{20}$ al cual acuden todos los peregrinos...

... Hay en Jerusalén cuatro puertas: la puerta de Abraham ${ }^{21}$, la Puerta de David ${ }^{22}$, la puerta de $\operatorname{Sion}^{23}$ y la puerta de Josafat ${ }^{24}$... delante del Templo que había antaño ... allí está el Templum Domini ${ }^{25}$, que era el sitio del Templo. Sobre él construyó 'Omar ibn al-Jațtab una gran y muy hermosa cúpu$1 \mathbf{a}^{26} \ldots$

Ya no tan exacto es nuestro viajero en su descripción cuando apunta:

«... Frente a ese lugar está el Muro Occidental: es uno de los muros que había en el Santo de los Santos y le llaman Puerta de la Misericordia; allí acuden todos los judíos a rezar ante el muro del atrio ... en la casa que fue de Salomón están las caballerizas que hizo edificar; es una construcción muy fuerte, de grandes piedras: no se ve edificación como ella en todo el país. Allí se ve, aun hoy día, la pileta donde los sacerdotes degollaban las víctimas. Todos los judíos que van allí escriben sus nombres en el Muro ${ }^{27}$..."

Y fuera de las murallas, Benjamín se extiende en los curiosos monumentos del monte Sion:

...Enfrente de Jerusalén está el monte Sion y no hay otro edificio ... sino una iglesia para los incircunciso ${ }^{28}$...en el monte Sion están las tumbas de la casa de David, mas no se conoce donde está el lugar ${ }^{29}$ pues hace quince años cayó un muro de la iglesia.Y dijo el Patriarca a su encargado: «toma las piedras de las murallas antiguas y edifica con ellas la iglesia". Así lo hizo; contrató obreros a salario acordado, en número de veinte e iban extrayendo las piedras de basamento de las murallas de Sion. Entre aquellos hombres había dos muy unidos por una gran amistad ... y llegó la hora de comer y sus compañeros se fueron a comer y ellos arrancaban las piedras y al levantar una piedra encontraron allí la entrada de una cueva ... caminaron por la entrada de la cueva hasta que llegaron junto a un gran recinto edificado sobre columnas de mármol, cubierto de plata y oro; ante ellos había una mesa de oro y el cetro y la corona: era el sepulcro del rey David y a su izquierda estaba el sepulcro del rey Salomón, de la misma manera, y así todos los sepulcros de todos los reyes de Judá allí enterrados. Había allí unos cofres cerrados que nadie sabe lo que contenían. Quisieron esos hombres entrar en el recinto y he aquí que un viento tempestuoso que salía de la boca de la cueva los golpeó; cayeron al suelo como muertos y yacieron hasta el atardecer. Y he aquí que vino un viento, gritando con humana voz «levantaos, salid de este lugam y salieron de allí, temerosos y a toda prisa. Fueron ante el Patriarca y le contaron estas cosas. El Patriarca ordenó traer 
ante él al piadoso asceta rabí Abraham Alconstantiní ... y le contó todas aquellas cosas, según el relato de los dos hombres que venían de allí. Respondió rabí Abraham diciéndole: «aquéllas son las tumbas de la casa de David, de los reyes de Judá; mañana entraremos yo, tú y esos hombres y veremos qué hay allím. Al día siguiente mandaron buscar a esos dos hombres, hallándolos acostados -cada uno en su lecho- temerosos, diciendo: «nosotros no entraremos alli, pues no es voluntad de Dios mostrarlo a los hombres». El Patriarca ordenó tapiar aquel lugar para ocultarlo a los hombres, hasta hoy.»

Prosiguiendo su periplo por la tierra de Israel, Benjamín llega hasta la frontera septentrional

«... hasta Banias, que es Dan ${ }^{30}$; hay allí una cueva y desde allí sale el Jordán ... Delante de la cueva se reconoce el lugar del altar del ídolo de Mija, que adoraban los danitas en aquellos tiempos. Asimismo está allí el lugar del ara de Jeroboam, que contenía el becerro de oro.

\section{c) Siria}

Ya en territorio sirio, Benjamín se detiene en la opulenta capital, Damasco, y se fija en la magnífica mezquita llamada

«... ŷami`a Dimašq ${ }^{31}$ : no hay construcción como ésta en todo el país. Dicen que fue palacio de Ben-Hadad ... dentro del patio [del palacio] hay una cabeza de gigante revestida de oro y plata, construida a guisa de fuente; los bordes son de oro y plata y es grande como una cisterna: pueden entrar en su interior, para bañarse, como unas tres personas. Allí, en el interior del palacio, está colgada una costilla del citado gigante, cuya longitud es de nueve palmos y dos palmos de anchura. Y se dice que era el rey gigante de los antiguos cíclopes, de nombre rey Abramaz, pues así lo encontraron grabado en una piedra, sobre su sepulcro, y estaba escrito que reinó sobre el mundo entero ${ }^{32}$."

Pasando por las estribaciones de la cordillera del Antilíbano, al norte, en el ameno valle de los ríos Orontes y Litani se encuentra nuestro viajero con la famosa

«...Baalbek, que es Ba`alot, en la Biq `a ${ }^{33} \mathrm{del}$ Líbano. Fue fundada por Salomón para la hija del Faraón ${ }^{34}$. La construcción del palacio es de grandes piedras, siendo la longitud de cada piedra veinte palmos y su anchura doce palmos. No hay nada entre piedra y piedra, diciéndose que no se hizo esta edificación sino por obra de Asmodeo $^{35}$."

Mucho más parco es, sin embargo, nuestro viajero en su descripción de la no menos renombrada Palmira

«...También Tadmor, que está en el desierto y fundara Salomón ${ }^{36}$... con grandes piedras. La ciudad de Tadmor está circundada de una muralla, en 
el desierto, lejos de lugar habitado y a cuatro jornadas de la mencionada Ba`alot".

\section{d) Mesopotamia}

Y ya en tierras mesopotámicas -la Babel o Babilonia de los judíosBenjamín pasa por la ciudad de Mosul $^{37}$ (que él considera es Ašur la Grande $^{38}$ ) y escribe

«... entre ella y Nínive hay sólo un puente y esta última está en ruinas, pero en medio de las ruinas hay aldeas y grandes ciudades. La extensión de Nínive se reconoce por las murallas, como unas cuarenta leguas hasta la ciudad de $\mathrm{Al}^{-B a l^{39}}{ }^{\text {. La ciudad de Nínive }}{ }^{40}$ está sobre la orilla del Tigris. ..."

Nuestro viajero se detiene en la capital califal, Bagdad, de la que nos ofrece una exhaustiva descripción tanto de las instituciones políticas y religiosas islámicas como de la opulenta comunidad israelita con sus dirigentes y sabios rabinos. A tres jornadas -pasando por Gaziga, también llamada Ras-`Ayn- llega Benjamín a

«Babel, que es Babel la antigua ${ }^{41}$, en ruinas, las cuales tienen una extensión de treinta millas. Todavía se encuentra allí el palacio derruido de Nabucodonosor y las gentes temen entrar en él debido a las serpientes y alacranes que hay en su interior. Cerca de allí, a una milla de distancia, viven tres mil judíos que rezan en la sinagoga 'Aliyat-Dani'el -la paz sea con él- : es la antigua camareta que edificara Daniel, construida con piedras talladas y ladrillos. Entre la sinagoga y el palacio de Nabucodonosor está el lugar del horno ígneo donde fueron arrojados Jananías, Misael y Azarías ${ }^{42}$ y es profundo..."

Prosiguiendo camino por tierras mesopotámicas, a cuatro millas de Hilah, Benjamín accede a un curioso monumento, que su fértil imaginación identifica con

«... la Torre que edificaron los de la generación que vivió la separación de las razas ${ }^{43}$, construida con ladrillos llamados âyurra $a^{44}$. La longitud de su basamento es de como unas dos millas, su anchura como unos cuarenta codos y su longitud como unos doscientos codos. Cada diez codos hay caminos y por ellos se sube, allí, en espiral, hasta arriba, contemplándose desde allí una extensión de veinte millas, pues el país es llano. Desde los cielos cayó fuego en su interior partiéndola hasta lo más profundo ..." 
480

José Ramón Magdalena Nom de Déu



Detalle de la ziggurat de Borsippa

(en la actualidad Birs Nimrud)

que la tradición considera la Torre de Babel 
e) Elam

Desde Basora, al sur de Mesopotamia, Benjamín pasaría a tierras iranias cruzando el río Samarra ${ }^{45}$ y

«... desde allí hay cuatro jornadas hasta Kuzistán ${ }^{46}$, que es Elam, la gran ciudad. No toda ella está habitada ya que está parcialmente en ruinas ${ }^{47}$, en medio de las cuales está $\mathrm{Susa}^{48}$, la capital, que fue el palacio del rey Asuero ${ }^{49}$. Había allí un gran edificio de tiempos antiguos.

\section{f) Egipto}

El tono del relato que nos ofrece el texto hebreo de Benjamín recobra visos de verosimilitud y se ajusta al medio que describe al llegar al Egipto fatimí ${ }^{50}$, tras su dilatada estancia en Bagdad, Basora y aledaños ${ }^{51}$.

\section{[El Cairo y el nilómetro]}

So ‘án ${ }^{52}$ está circundada por una muralla y El Cairo no tiene muralla, pues el Nilo la rodea por el otro lado. Es una gran ciudad y en ella hay muchos zocos y alhóndigas; asimismo hay muchos judíos ricos en ella. No cae lluvia, ni hielo ni nieve se ha visto en ella nunca. El país es muy caluroso. El Nilo se desborda una vez al año ${ }^{53}$ en el mes de 'elul ${ }^{54}$, cubriendo toda la tierra y regándola en una extensión de quince días; las aguas permanecen durante los meses de 'elul y tišri ${ }^{55}$, regándola y saciándola. Para saber la medida de la subida del Nilo tienen una pilastra de mármol de ingeniosa factura que está sobre una isla, dentro del agua; tal pilastra está a doce codos sobre el nivel de las aguas $^{56}$ y cuando sube el Nilo y la cubre saben que ya subió el Nilo y cubrió el país de Egipto en una extensión de quince jornadas. Si cubrió la mitad de la pilastra, no cubrirá sino medio país. Un hombre mide cada día la pilastra y pregona en Șo án y en El Cairo, diciendo:-«Alabad al Creador, pues el Nilo subió hoy tanto y tanto!». Cada día él mide y pregona ${ }^{57}$. Si las aguas cubren toda la pilastra hay abundancia en todo Egipto y el Nilo sube poco a poco hasta que cubre el país en una extensión de quince jornadas.

Desde el Nuevo Cairo al Viejo Cairo ${ }^{58}$ hay dos leguas: éste está en ruinas y hasta hoy día se ve el lugar de la construcción de las murallas y de las casas.

\section{[Las pirámides]}

A unos quince km. al S.O de El Cairo, ya en pleno desierto, se topa Benjamín con las colosales pirámides, que él describe según su peculiar manera, cuajada de referencias al texto bíblico: 
También allí, en todos los lugares, hay muchísimos graneros ${ }^{59}$ hechos por José -la paz sea con él- construidos con cal y piedras: es obra muy sólida. Hay allí un obelisco ${ }^{60}$ hecho por arte de encantamiento, no viéndose cosa tal en todo el mundo.

\section{[Heliópolis]}

Y a un par de $\mathrm{km}$. al NE de la capital fatimí, nuestro viajero llega a la antigua Heliópolis,

Desde allí hay media jornadas hasta 'Ayn al-Šams, (que) es Ra`amsés ${ }^{61}$. Está en ruinas. Allí hay (restos) de las construcciones que edificaron nuestros antepasados: torres construidas con ladrillos ${ }^{62}$.

La andadura final del trotamundos navarro por tierras egipcias le lleva al importante puerto de Alejandría. Y desde allí, por tierra, hasta Damieta, embarcando y poniendo proa a occidente para regresar definitivamente a Sefarad. De Alejandría nos deja una jugosa relación de sus monumentos y antigüedades más curiosas.

\section{[Alejandría: el faro y otros monumentos]}

Desde allí hay dos jornadas hasta Alejandría de Egipto, (que) es Amon de $\mathrm{No}^{63}$. Pero cuando la fundara Alejandro (el) Macedonio la llamó según su nombre y la edificó muy fortificada y bella; las casas, los palacios y las murallas son de construcción muy bella ${ }^{64}$. Fuera de la ciudad está la Academia de Aristóteles ${ }^{65}$, maestro de Alejandro; hay allí un gran edificio y una columna de mármol entre madraza y madraza. Allí hay como unas veinte madrazas a las que allí iban (gentes) de todo el mundo para aprender allí la sabiduría de Aristóteles el filósofo. La ciudad está construida hueca por debajo mediante puentes; la construyó con gran sabiduría ${ }^{66}$. Sus calles son rectas; en su interior, en los canales que uno ve, los hay de una milla de distancia, de puerta a puerta: desde la puerta de Rašid hasta la puerta del Mar. Allí construyó una vía sobre el puerto de Alejandría, de una milla de distancia dentro del mar. Hizo allí una gran torre llamada El Faro ${ }^{67}$ y en lengua árabe minar al-Iskandariyya. Allí, sobre lo alto de la torre, hay como un espejo de cristal. Todas las embarcaciones que van a ella para guerrear o causarle daño, sea del país de Grecia o del país de Occidente, lo veían desde una distancia de veinte jornadas a través del espejo de cristal $^{68}$...

Allí, sobre la orilla del mar, hay un sepulcro de mármol y en él están grabadas toda clase de fieras y aves, y su imagen en su interior ${ }^{69}$. Todo (está) en escritura de los tiempos antiguos: nadie conoce la escritura ${ }^{70}$. Dicen que se supone que era un rey de los tiempos antiguos, anterior al diluvio. El sepulcro tiene quince palmos de largo y seis de ancho. 


\section{Testimonios arqueológicos del Oriente Próximo...}

\section{Notas}

1 Hay que descartar ya la equivocada suposición de que era oriundo de Toledo, confusión que han mantenido algunos eruditos - el primero fue Benito Arias Montano- aduciendo una posible metátesis de las dos últimas consonantes del topónimo.

2 Tal como se refleja en algunas voces y frases aljamiadas hebraicorromances y hebraicoárabes del texto manuscrito..

3 Cita, por ejemplo, a los emperadores Tiberio, Nerón, Vespasiano y Tito, a Alejandro el Magno, al filósofo Aristóteles, etc.

4 Tal es la opinión de ABrahams, I. (1937): Jewish Life in the Middle Ages, cap. XI Trades and Occupations, New York, pp. 211-213.

5 Edición de Amsterdam, $1712 \mathrm{f}^{\circ} 99 \mathrm{v}^{\circ}$.

6 Asher, A. (1840): Sefer Masa`ot. 2 volúmenes. Berlin.

7 ADLER, M.N. (1907): The Itinerary of Benjamin de Tudela. Oxford.

8 CARMOLY, M. (1847): Itineraires de la Terre Sainte des XIII à XVII siècles, traduits de l'hébreu et accompagnés de tables, de cartes et d'éclaircissements. Bruxelles; CARMOLY, M. (1852): Notice historique sur Benjamin de Tudèle; nouvelle édition suivie de l'examen géographique de ses voyages par J. Lelewel. Bruxelles et Leipzig. Hay otra traducción al francés, anterior -y muy inferior en calidad- a la de Carmoly, a cargo del joven erudito BARRATIER, J.P. (1734): Voyages de Benjamin, fils de Jona de Tudèle, en Europe, en Asie \& en Afrique, depuis l'Espagne jusqu'à la Chine, traduits de l'Hébreu par - (Amsterdam).

9 Tengo noticia de que un cualificado investigador de la Universidad Hebrea de Jerusalén está ultimando una nueva y muy completa edición crítica del texto, en base a todos los $m s s$. y ediciones conocidos. Al parecer, se incluirá un nuevo documento hebreo del siglo XIV, recientemente identificado entre los fondos de las colecciones Fírkovitch (Biblioteca Nacional de Rusia, San Petersburgo) y que aportaría importantes novedades y rectificaría no pocos aspectos del tramo final del periplo de Benjamín.

10 KRAUS, S. (1937): New Light on Geographical Informations of Eldad Ȟadani and Benjamin of Tudela.Tarbitz, Jerusalem, pp. 208-323. [en hebreo]; DuBLER, C.E. (1953): Abu-Hamid el granadino y su relación de viajes por tierras eurasiáticas. Madrid, pp. 236 y ss.

11 El Giblet o Gebal, la antigua Biblos fenicia, situada sobre una suave colina junto al mar, a $34^{\circ} 8^{\prime}$ de latitud nôrte. Los textos de Ezequiel 22,9 y el Salmo 83,8 acaso sugiriesen a Benjamín la existencia del ídolo y templo amonita que luego describe.

12 La ciudad fenicia de Tiro se erigió primitivamente por los sidonios -y según Josefo, dos siglos antes que el Templo de Jerusalén- en la costa continental, frente a una isla rocosa, bastante llana y de reducida extensión (unos $1.400 \mathrm{~m}$. de largo por unos $1.000 \mathrm{~m}$. de ancho), a unos $500 \mathrm{~m}$. de la costa. Posteriormente, en época difícil de precisar, pero que parece se remonta a la época de Hiram, se extendió por la isla y este nuevo barrio insular eclipsó en importancia al barrio continental, conocida posteriormente como la Paleotyrus o ciudad vieja. La ciudad nueva tenía dos puertos naturales, el septentrional llamado sidonio y el meridional llamado egipcio, junto al que había una isleta, unida artificialmente a Tiro, llamada de Hércules o de Melkart, donde debía estar el templo de esta divinidad. Durante el asedio de Alejandro el Magno se construyó un dique terrero de $400 \mathrm{~m}$. de longitud, uniéndola a la costa como istmo de artificial península. Debido a la erosión marina, se ha consolidado el istmo por acumulación de arenas y tierras provocando que la isleta de Melkart esté actualmente cubierta por las aguas del mar en su mayor parte. La 
descripción de Benjamín se ajustaría perfectamente a la realidad geográfica y monumental de la antigua ciudad fenicia a finales del siglo XII.

13 I Reyes 18, 30-32.

14 I Reyes 16, 32-33.

15 Es una de las torres de la Ciudadela, cuya construcción data de la época del Segundo Templo. Los enormes ortostatos a que se refiere nuestro viajero son de época herodiana, visibles hoy día.

${ }^{16} \mathrm{La}$ Ciudadela fue destruida parcialmente en 1219 por el mameluco Al-Mu'azzim, restaurada en 1247 por Al-Malik As-Salih 'Ayyub; de nuevo restaurada en 1310 por Nașr Muhammad ibn Kalawn y, finalmente, en el siglo XVI, el sultán Solimán el Magnífico agregó la mezquita y la puerta principal.

17 Es el de los caballeros de la Orden del Hospital de San Juan de Jerusalén, fundado por el noble provenzal Gerard en 1048. Inicialmente tuvo una finalidad benéfica y caritativa, acogiendo a los peregrinos cristianos enfermos, pero después se incluyó el voto del servicio militar a los frailes sanjuanistas. La sede se trasladó a Acre en 1187, tras la caída de Jerusalén y a Rodas en 1291.

18 Es el Templum Salomonis, cuartel que fue de los caballeros Templarios de Jerusalén, instalado en la explanada del antiguo Templo de los judíos, sobre la mezquita AlAqsa.

19 El Santo Sepulcro, en el corazón del barrio cristiano de la ciudad.

20 Respetuoso circunloquio de Benjamín para referirse a Jesús, el de los cristianos.

21 También llamada entonces puerta de San Esteban es la actual puerta de Damasco.

22 Es la actual puerta de Yaffa.

$23 \mathrm{El}$ nombre se ha mantenido idéntico hasta nuestros días.

24 Es la actual puerta de los Leones.

25 El Templo de Jerusalén se erigía sobre el monte Moriah. Los cruzados convirtieron el Domo de la Roca, lugar de plegaria para los musulmanes, en iglesia dedicada al culto.

26 Este oratorio islámico, de planta octogonal y hermosa cúpula dorada, se alza sobre un muy especial peñasco del monte Moriah, tenido por la tradición como lugar del sacrificio de Isaac (Gen. 22, 2 y siguientes).

27 Esta descripción es muy confusa y Benjamín mezcla informaciones recibidas de terceras personas con sus propias experiencias de visitante a los lugares que describe. El Muro Occidental nada tiene que ver con el Sancta Sanctorum o Qódeš-ha-Qodašim ni está frente al Domo de la Roca, sino a un centenar de metros al SW, la Puerta de la Misericordia (tapiada a cal y canto hasta hoy) está justo en la muralla oriental y las caballerizas de Salomón (a la sazón utilizadas como establos por los Templarios) están justo al lado de la mezquita Al-Aqsa (entonces Templum Salomonis).

${ }^{28}$ Es la iglesia de Santa María del Monte Sion y los incircuncisos son, por exclusión obvia, los cristianos.

${ }^{29}$ La curiosa historia que sigue fue traducida y comentada por ARCE, A (1963) El sepulcro de David en un texto de Benjamín de Tudela. Sefarad, Madrid pp. 105-115.

30 También llamada Cesarea de Philipo.

31 Es la famosa Mezquita de los Omeyas. Fue templo romano, después el emperador Teodosio I hizo levantar una basílica de columnas en tres naves dedicada a San Juan, en conmemoración de la cabeza del Bautista, conservada entonces en el sagrario y posteriormente llevada la preciosa reliquia a Constantinopla. Tras la conquista de la ciudad por los musulmanes, éstos se apropiaron de la mitad oriental del edificio. En 705, el cali- 


\section{Testimonios arqueológicos del Oriente Próximo...}

fa Walid retiró a los cristianos el uso de la parte occidental y reedificó la iglesia convirtiéndola en mezquita en 708 .

${ }^{32}$ Cfr. Midraš Rabbah, cap. XIV: «Dijo rabí Leví: el gran hombre entre los gigantes es Abraham".

${ }^{33}$ Es el valle o vega de los ríos Orontes y Litani, en la Celesiria.

34 Aquí -como en otras ocasiones- se deja llevar Benjamín por su fantasía y falta de información. Las ruinas romanas de Baalbek son los restos de dos antiguos templos (el de Júpiter y el de Baco) erigidos en una espectacular acrópolis, más reedificaciones de época bizantina e islámica. Destacan la escalinata de acceso a los propileos, que dan acceso a un antepatio comunicado a un gran patio interior por una puerta. Allí hay una basílica y unos baños bizantinos, dos piscinas, los antes citados templos, una torre fortificada y un recinto amurallado con torretas y puertas. Nada de lo allí construido se debe al rey bíblico citado por Benjamín.

35 Según el libro de Tobías cap. III y IV -no incluido en el canon hebreo- Asmodeo es el espíritu maligno que mató a los siete primeros esposos de Sara, hija de Ragüel. El nombre hebreo 'Ašmeday se ha querido relacionar con Eshmadeva, uno de los siete espíritus malos del ámbito cultural iranio. Según diversas tradiciones rabínicas aparece como jefe de los demonios (cfr. Targum Qohélet, I, 12) y que el mismo rey Salomón lo dominó y le obligó a trabajar en la construcción de su famoso templo, en la que no usó jamás ni martillo ni herramienta alguna, empleando únicamente una piedra especial con la que partía y encuadraba las rocas más duras.

36 El topónimo Tadmor - Tudmur procede del étimo hebreo tamar (=palmera). Se ha discutido si correspondería a la mítica Tamar que edificara Salomón en el desierto, tradición que recoge Benjamín de Tudela y da como cierta. Fue importante centro caravanero, destacando sus numerosos templos, especialmente el del Sol, torres, arcos y murallas de construcción romana.

37 Es bastante probable que en época asiria fuese Mosul un arrabal de Nínive, si bien algunos autores han creído ver en ella la antigua Mespila citada por Jenofonte. La primera noticia cierta de esta ciudad es del año 636, ya en época musulmana y entonces se llamaba Al-Mawsil (=«el paso»), porque venía a serlo entre occidente y oriente.

38 Ašur, hijo de Sem, huyendo de la tiranía de Nimrud, fundó la ciudad que llevaría su nombre; después se denominaría Nínive, en honor al gobernador Nino, considerado por tradición legendaria como fundador del imperio asirio.

39 Sin duda la ciudad de Arbelas, cuyo nombre en semítico asirio 'arba -íl $\cdot \mathbf{l u}$ significa "[ciudad de los] cuatro dioses». Famosa en la antigua Asiria por ser uno de los principales lugares del culto de la diosa Išhtar y la única población asiria hoy existente que ha conservado su nombre primitivo.

40 Diodoro describe a Nínive en forma de un triángulo de 150 estadios de longitud por 90 estadios de anchura y 480 de perímetro, unos $105 \mathrm{~km}$. en total. Sus murallas tenían $33 \mathrm{~m}$. de altura y estaban rematadas por 1,500 torres de $60 \mathrm{~m}$. de altura. Las numerosas -y a menudo poco metódicas excavaciones-, a partir de 1821, han puesto a contribución de arqueólogos e historiadores y eruditos importantes hallazgos: los templos de Ašhurbanipal, con parte de su importante biblioteca, de Senaqerib, así como otros objetos escultóricos y arquitectónicos de especial interés.

41 Benjamín de Tudela es el primer europeo en dar noticia de las ruinas de Babilonia.

42 Daniel, 3, 12-30. Es la conocida historia de los tres piadosos judíos arrojados al pozo ígneo por negarse a adorar el ídolo construido por Nabucodonosor. 
43 Se refiere aquí el viajero judeonavarro a la no menos famosa Torre de Babel y a la confusión de las lenguas, tal como relata Génesis 11, 7 y siguientes. Sin embargo, el monumento que describe Benjamín es, en realidad, la ziggurat de Borsippa (hoy Birs Numrud), la cual fue tenida durante mucho tiempo por la Torre de Babel (cfr. Be-re šit rab$b a h, 38$ ). Actualmente tiene $47 \mathrm{~m}$. de altura y sus ladrillos quedaron parcialmente vitrificados bajo los efectos de un violento incendio. Otros autores creían que el relato de Benjamín se refería a la ziggurat Etemenanki (=«casa del fundamento del cielo y la tierra»), que fue identificada por el asiriólogo Hilprecht en 1913.

44 Es voz árabe -tomada del persa "agur»- que en Alandalús dio «lâyura», pronunciado «laŷora») y de la que procedería la «rajola» catalana o ladrillo cocido. Estos ladrillos vitrificados o quemados por el fuego de los cielos los relacionaría la erudición bíblica de Benjamín con Isaías 27, 9.

45 Es el afluente Nahrvan, llamado también Diyaleh, o el Ab-i-Shirvan persa, formado por la confluencia del Holvan y del Zerchinar. En la moderna traducción italiana de Benjamin de Tudela. Libro di viaggi. A cura di Laura Minervini (1989) Palermo, p 115 y nota 112: «...Samara o Saimarreh Rud: nome di un tratto del fiume Kerkha, nel Kuzistan ..."

46 También Susistán, Susiana o Arabistán, que es la Elam bíblica.

47 Son las ruinas del palacio real de Atajerjes II (405-359 a. J.C.), en Susa.

48 Es la Šošán del relato bíblico de Ester y antigua capital de Elam.

49 Ester, 1, 1-3.

50 Reinaría entonces el último monarca de aquella dinastía, Al-'Adid (1160-1171).

51 Todo cuanto nos relata Benjamín sobre Arabia, Qiš, Ceylán, Quilón y la China -así como otros materiales legendarios que recoge su relato- debió oírlo contar a fantasiosos e ingenuos informantes y es más que dudoso que nuestro viajero alcanzase tan lejanas latitudes.

52 Se refiere a la bíblica So án Mișráyim citada en Números 13, 22 y correspondería a la antigua Tanis o Avaris de los hyksos, situada en el delta oriental, no lejos de El Cairo.

53 Cfr. BejaRANO, InGRID (1991): Abu Hamid al-Garnati (m. 565/1169). Al-mu rib `an bad `aŷa'ib al-Magrib. (Elogio de algunas maravillas del Magrib). Introducción, edición y traducción por - Madrid, pp. 162-163: «No llueve ni en verano ni en invierno. Únicamente ... se derrama el Nilo y se inunda de él la tierra ...». Es Plinio (Nat. Historia V, 57-58 y XVIII 167-168) el clásico que con mayor exactitud describió las crecidas del Nilo, si bien el fenómeno mereció la atención de Herodoto (II, 20), Lucrecio (VI, 712-732) e incluso San Isidoro (De Rerum Natura, XLII y Etymologiae XIII, 21).

54 Último mes del calendario hebraico.

55 Primer mes del calendario hebraico.

56 Abu Hamid al-Garnati ..., p. 164: «... hay una columna de mármol blanco, pulido, cuya longitud es de veinticuatro codos ...» y en nota 9: "En la antigüedad había nilómetros en Tebas, Menfis, Assuán y otros lugares, quedando restos arqueológicos de ellos; cf. K. Michailowski, L'art de l'Ancienne Égypte (París, 1971), p. 546. En época árabe las crecidas del Nilo se medían por medio de una sonda ..., pero luego aparecen también los nilómetros... consistentes en un pozo revestido de sillería en cuyo centro se levantaba una columna octogonal con una escala grabada en antiguos codos árabes, equivalentes cada uno a 0,54 m». El nilómetro que describe Benjamín es el situado en la isleta de Rawda, no lejos de Fustat.

${ }^{57}$ Abu Hamid al-Garnati ..., p. 163: « ... Y si aumenta el agua y alcanza los doce brazos, anuncia un pregonero cada día: "Dios ha hecho crecer el Nilo bendito tanto y tanto ...". 


\section{Testimonios arqueológicos del Oriente Próximo...}

58 El Nuevo Cairo fue fundado en el año 969 por Al-Ŷawhar, comandante del ejército fatimí; en 972 recibió el nombre definitivo de Al-Qahira (= la victoriosa) cuando llegó el califa Al-Mu izz y estableció en ella la capital del imperio. El Viejo Cairo (Al-Misr alQadima) corresponde a la antigua población de Fustat, levantada en 641 por el general conquistador de Egipto `Amr ibn al-`As al-Sahmi, compañero del Profeta. Cfr. MANN, JAсов (1979): The Jews in Egypt and Palestine under the Fatimid Caliphs, New York.

59 Referencia a Génesis 41, 49-56. Según González Llubera (p. 165): «... los graneros ... datan de Ramsés II. (Fayum) és célebre por la asombrosa fertilidad de sus alrededores, regados por el canal de José, Bahr Yusuf, a cuyo personaje bíblico atribuye la tradición árabe su construcción».

60 González Llubera (p. 112) traduce la voz hebrea ‘amud por «pirámide». Abu Hamid al-Garnati ..., p. 168: « ... y se trata de unas pirámides grandes que están en frente de alFustat ... y son tres. Una de ellas pequeña, construida de piedra de mármol ...».

61 Topónimo citado en Génesis 47, 11 y Éxodo 1, 11.

62 En árabe «manantial del Sol», es decir, Heliópolis, a unos $12 \mathrm{~km}$. Al nordeste de El Cairo, en la actual Tel-al-Hisn. Cfr. ADLER, M.N. (1907): The Itinerary of Benjamin de Tudela. Oxford, p. 74 y nota 3 . Es el yacimiento de la antigua Pi-Re, más conocida como Unu, también On. Era uno de los nomos del Bajo Egipto y anunque no desempeñó papel político relevante, sí destacó como centro religioso de gran influencia. El antiguo templo fue la cuna de un conjunto de creencias relacionadas con el culto solar. Para las construcciones hechas con ladrillos edificadas por los antepasados israelitas a que se refiere Benjamín, cfr. Éxodo 1, 11.

${ }_{63}$ Es, en realidad, Tebas, en el alto Egipto. Benjamín confunde - una vez más- el topónimo bíblico.

64 Fundada por Alejandro el Magno en 332 a. J.C. sobre el emplazamiento de Rako$t i s$, un antiguo poblado portuario egipcio frecuentado de antiguo por marinos fenicios.El plan urbanístico de la ciudad era de calles en ángulo recto, según la fórmula helena, y fue terminado en tiempos de Polomeo II Filadelfio (308 a.J.C. - 246 a.J.C ).

65 Abu Hamid al-Garnati ..., pp. 158-159 describe el lugar como «... un edificio construido en piedra tallada y sobre él hay una sala que construyó el genio para Salomón, cobre él sea la paz, con columnas de mármol que no tiene igual ... en el centro de la sala hay una columna de mármol que está sobre un pedestal del mismo mármol que el de las otras columnas; su altura es de ciento veinte codos, su longitud se mide por la sombra, la circunferencia de la columna es de cuarenta y cinco palmos ...».

66 Abu Hamid al-Garnati ..., p. 155: «... hay muchos edificios sobre la tierra y bajo la tierra. Entré en una de las bóvedas que hay debajo de la tierra de Alejandría, y cuya altura era de de veinte codos y su anchura de ocho codos. Estaba construida en roca tallada y no se le parece a ninguna otra construcción. Esa bóveda va desde el comienzo de la ciudad hasta su final. Debajo de la tierra, semejante a esa bóveda, iguales a ella en anchura y en longitud, hay muchas bóvedas que se comunican unas con otras».

66 Ptolomeo I Soter (367 a.J.C. - 283 a.J.C) unió la isleta de Faros a la tierra firme mediante la construcción de una vía de siete estadios de longitud. El Faro fue construido en la primera mitad del siglo III a. J.C. en la isleta por Ptlomeo II Filadelfio. El edificio constaba de tres cuerpos superpuestos: una torre de planta cuadrada con ventanas de 30 $\mathrm{m}$. de lado y 60/70 m. de altura; sobre ésta se levantaba una segunda torre de planta octogonal, también con ventanas, de unos $40 \mathrm{~m}$. de altura y, por último, una linterna de casi $10 \mathrm{~m}$. rematada por una estructura cónica que soportaba la colosal estatua de Poseidón, el dios de los mares. La luz, producida por la combustión de aceites y materias resinosas, 
se reflejaba mediante ingenioso sistema de espejos y era visible desde larga distancia. Con todo, la esfericidad de la tierra sólo permitiría su avistamiento a una distnacia máxima de unos $40 \mathrm{~km}$. El Faro de Alejandría era una de las siete maravillas de la antigüedad.

68 El Faro tendría las siguientes funciones: 1) atalaya para observar las naves procedentes de Grecia, 2) instrumento bélico que permitía quemar las naves hostiles, 3) instrumento para transmitir señales heliográficas y 4) de talismán. Cfr. ASÍN PALACIOS, M (1935): Nuevos datos sobre el Faro de Alejandría, Al-Andalus I, Madrid pp. 185-193 y Abu Ḥamid al-Garnați ..., p. 157: «... se cuenta que sobre él había un espejo, en el que se veía a quien llegaba por el mar de los Rum a una distancia de varios días y noches, según se cuenta...".

69 Este conjunto monumental no lo he sabido identificar con precisión. Acaso se prefiere Benjamín a los restos del Caesareum, bien descrito por Plinio (Hist. Nat. XXXVI, XIV, 8). Era el templo construido por Cleopatra en honor a Antonio. Inacabado, fue terminado por Augusto y consagrado a su culto imperial. Allí se erigieron las Columnas de Cleopatra, sendos obeliscos reutilizados procedentes de Heliópolis. Actualmente uno está en Londres y el otro en Nueva York.

70 Primera alusión a la escritura jeroglífica egipcia, descifrada entre 1822 (Lettre à M. Dacier sur les hiéroglyphes phonétiques) y 1824 (Précis du système hiéoglyphique des anciens Égyptiens) por el pionero de la moderna egiptología, Jean François Champollion. 